\title{
¿Hacia dónde van las ciencias sociales?
}

\footnotetext{
$7 n$ el Centro de Investigaciones y Estudios Superiores en Antropología Social se lle-1 vó a cabo, el pasado 9 de abril de 2003, una mesa redonda referida a las actuales perspectivas de las ciencias sociales. A la misma asistieron los coordinadores de posgrado de la Escuela Nacional de Antropología e Historia, del Instituto de Investigaciones José María Luis Mora, de la Universidad Nacional Autónoma de México, de la Universidad Iberoaméricana y del CIESAS. El evento contó con la participación del sociólogo francés Michel Wieviorka, con su conferencia “iHacia dónde van las ciencias sociales?", después se dio una ronda de comentarios y preguntas alrededor del tema expuesto.

Por el gran interés que generó la temática planteada por Wieviorka y la discusión propiciada por la misma respecto a la necesidad de considerar la interacción mutua en las ciencias sociales, sus objetos, enfoques, razonamientos y paradigmas, así como incorporar la noción de las identidades colectivas, la revista Desacatos se dio a la tarea de agrupar las distintas intervenciones y dar a conocer este debate presente hoy en día en el quehacer científico.
}

Desacatos, núm. 12, otoño 2003, pp. 115-129. 


\section{Michel Wieviorka:*}

El tema más general que quisiera tratar hoy es: ¿̨hacia dónde van las ciencias sociales?; y de manera más particular, aunque no soy antropólogo: ¿̨hacia dónde va la antropología en la evolución actual de las cosas? Por supuesto, mi formación es más bien sociológica, por lo tanto partiré de lo que mejor conozco, pero intentaré compartir con ustedes, antropólogos en su mayoría, algunas reflexiones.

Me parece, y es mi punto de partida, que las ciencias sociales en general salieron ya de su época clásica. No sé si pasa lo mismo en antropología, pero para mí es evidente que la cumbre de la edad clásica es Parsons. Es decir, el momento en que este gran sociólogo intenta integrar, en un mismo conjunto de ideas a Max Weber, Emile Durkheim, Pareto y uno que otro más. Y como bien lo saben los sociólogos, excepto aquéllos que se olvidaron por completo de lo que fue el funcionalismo, todo esto se derrumbó. Esta gran construcción piramidal, así como la concebía Talcott Parsons, se desmoronó, quizá por los movimientos estudiantiles, los movimientos en contra de la guerra años en el campo de la sociología, o sea, desde el derrumbe del funcionalismo parsoniano, mismo que podemos ahora olvidar para entrar en la discusión.

El mundo ha cambiado tanto en los últimos treinta años, que todos nosotros en las ciencias sociales tenemos que redefinir, primero, nuestros objetos, segundo nuestros paradigmas y, tercero, los contornos o los límites de nuestras disciplinas, la manera cómo se articulan entre sí y cómo se articulan, quizá, con otros campos del conocimiento, fuera de las ciencias sociales en el sentido estrecho de la palabra.

Hay tres ejes fundamentales en la discusión que Rafael Loyola me pidió abrir con ustedes: por un lado, nuestros objetos, por el otro, nuestros enfoques, razonamientos, paradigmas, y finalmente, el espacio propio de cada una de nuestras disciplinas y sus interacciones mutuas. No les voy a edificar un panorama general de las transformaciones del planeta desde hace cuarenta años. Abordaré un aspecto particular que me parece central.

La imagen que tengo de la antropología, y con la que probablemente varios de ustedes estarán en desacuerdo, es la siguiente: en el pasado la antropología se interesaba por grupos humanos lejanos, ajenos a Occidente. Había una suerte de división del trabajo: la sociología se interesaba por las sociedades más bien occidentales y la antropología por sociedades más bien lejanas.

Exagerando un poco, diría que cuando uno estudiaba la problemática de la familia en Londres, era sociólogo, pero cuando estudiaba el parentesco en Nueva Guinea o en Papuasia, era antropólogo. Por consiguiente, el investigador en antropología, según la imagen que tengo, era alguien que viajaba muy lejos y se quedaba mucho tiempo en esas tierras lejanas. Se instalaba en su terreno, y se quedaba allí uno o dos años, a veces de manera muy respetable, pero a veces también en las arcas del colonizador, no lo olvidemos.

Hoy no se puede pensar el mundo de esta manera. Sin duda, algunos lugares subsisten al margen de la modernidad, pero fuera de estas excepciones sabemos que el planeta se unificó. Quizá la palabra globalización no es la más idónea para describir lo que estoy evocando, ya que la globalización nos sugiere de inmediato problemas económicos, flujos financieros, mercados que se abren
* Michel Wieviorka es director de estudios en la Escuela de Altos tervención Sociológicos (CADIS) y de Cahiers Internationaux de Sociologie (junto con Georges Balandier). También es miembro de los comités de redacción de las revistas científicas Journal of Ethnic and Migration Studies, Ethnic and R Studies, Beyond the Divide, Presses de Sciences Po', Critical Horizons, French Politics, Culture and Society. Sus trabajos más actuales se refieren a multiculturalismo, racismo, violencia y diferencias culturales. 
por doquier; pero en todo caso, la planetarización, la mundialización, para utilizar otros términos, en sus dimensiones no sólo económicas, sino también culturales y sociales, cambió por completo las cosas.

A partir de esto, los grupos que tradicionalmente estudiaban la antropología, los problemas que abordaba, se transforman. ¿Por qué? Porque estos grupos, estos problemas, estos objetos que estudiaban los antropólogos en tierras lejanas se encuentran ahora en nuestras sociedades, y no sólo están adentro, sino que también circulan. Los grupos siguen lógicas de migración, de diáspora.

Por ejemplo, estoy muy impresionado por la evolución de la palabra "diáspora". Hace apenas algunos años, la idea de diáspora remitía principalmente al mundo judío, quizá al de los armenios, o los palestinos. Hoy en día, las diásporas están por todos lados. Prueba de ello, la revista Diásporas (en plural), que a lo mejor algunos de ustedes conocen.

México es un buen ejemplo de lo que estoy diciendo. Estábamos algunos de nosotros en un coloquio en Saltillo, donde se habló de indígenas que conservan bases muy sólidas en el campo mexicano y viven en el norte de Estados Unidos, con redes, modos de transportarse, medios de comunicación. Me parece hoy que el problema de la diferencia cultural, el problema del alejamiento cultural, no sólo es un problema de comunidades o grupos muy alejados, sino que nos remite a lo que está sucediendo en nuestras sociedades.

Ahora lo plantearé de manera distinta: me parece que los problemas que tradicionalmente estudiaba la antropología, que remitían a la imagen de sociedades situadas al margen de la modernidad, son problemas propios de la modernidad que actualmente vivimos. Por lo tanto, estudiar lo que nos parece propio de la antropología, como las diferencias culturales, es estudiar la modernidad.

Esto implica cambios muy importantes en nuestras maneras de pensar. Primero tenemos que acabar definitivamente con las ideas evolucionistas. La mayoría de nosotros ya lo sabemos, pero hay que decirlo con claridad. Y debemos definir mejor la modernidad. Lo digo también para los antropólogos.

Los sociólogos hablan de estas cuestiones desde hace tiempo, aunque no siempre con éxito. Desde los años setenta, ochenta, después de los arquitectos, se interesaron por la idea de posmodernidad.

No quiero entrar en estos debates; pero en todo caso, la idea clásica que heredamos del siglo XVIII y que decía que la modernidad es las luces, la razón, el progreso que poco a poco acaba con la tradición, las culturas, las religiones; esta imagen evolucionista del progreso de la modernidad que le gana a las identidades particulares, pues ya no podemos aceptarla. Es falsa empíricamente, y vemos que nuestras sociedades, hasta las más avanzadas, son sociedades que debemos definir por la presencia cada vez mayor de particularismos culturales.

Lo diré de otra manera, pero la idea sigue siendo la misma: ya no podemos conformarnos con oponer relativismo y universalismo. Ya no podemos escoger entre una perspectiva exclusivamente universalista, o exclusivamente relativista. Ya no podemos oponer lo que han sido las grandes orientaciones de las ciencias sociales y en particular de la antropología. Tenemos que aprender a conciliar los valores universales con los particularismos culturales, y conciliarlos en nuestros razonamientos de investigadores en ciencias sociales, y con más razón si tenemos preocupaciones políticas o de filosofía política.

Entonces, si lo que digo les parece atinado y merece debatirse, verán inmediatamente sus consecuencias para las ciencias sociales y, en particular, para la antropología.

La antropología tiene que estudiar comunidades, redes, grupos susceptibles de una gran fluidez y gran inestabilidad, que pueden estar muy alejados o muy cercanos a nosotros, y a veces las dos cosas simultáneamente: muy cerca y muy lejos.

Hablaba hace poco con una colega antropóloga que me decía que estaba estudiando en una comunidad indígena de México cómo los rituales de no me acuerdo qué fiesta se transformaban considerablemente por la migración, las redes con Estados Unidos, etcétera. Por lo tanto, hay que ser capaz de pensar este tipo de fenómenos: tanto lo que sucede en las regiones agrícolas de Estados Unidos a donde van a trabajar los indígenas, como lo que sucede en su pueblo de origen donde todo se transforma.

Esto plantea un montón de preguntas. Primero, la competencia que evocaba hace rato con la sociología: ¿̨cuál 
es la diferencia entre estudiar, como sociólogo o como antropólogo, problemas típicos de la modernidad hoy?

Pertenezco a una institución donde trabajo junto a personas como Marc Augé, que ustedes seguramente conocen, o Marc Abelés. Marc Augé empezó su carrera de antropólogo como africanista. Pero si se le conoce hoy en el mundo entero, es por sus paseos en el jardín del Luxemburgo en París, o por sus observaciones en el metro parisino. Marc Abelés, también antropólogo, nos propone actualmente estudiar el funcionamiento del parlamento europeo, u otras instituciones políticas europeas. Estamos, pues, frente a antropólogos que "cazan", por así decirlo, en los terrenos de los sociólogos. Muchos son los que observan este tipo de cosas.

Al preparar nuestra reunión estaba pensando en mi colega Bruno Latour, que un día hizo el libro que le dio fama, hace ya veinte años. Se fue al laboratorio de uno de sus parientes, premio Nobel de no me acuerdo qué disciplina científica, y le dijo: "Vengo a estudiar la ciencia, el trabajo científico, con los métodos de los antropólogos; voy a observar el trabajo que están haciendo", etc. Con todo esto podemos observar, en primer lugar, que las cosas pierden nitidez, que se van borrando las fronteras entre la sociología y cierta concepción renovada de la antropología.

Pero debo avanzar un poco más en lo que les dije acerca de las identidades culturales, porque es muy importante para la idea principal que estoy tratando de presentarles. Quisiera plantearles una idea que obliga a la antropología a transformarse de manera radical y acelerada. Pueden no aceptarla.

Si observo lo que ha sido la antropología en su historia, aunque es cierto que no soy especialista, primero fue una antropología física. Fue terrible. Quizá algunos lo recuerden. Yo me acuerdo perfectamente bien, tomé uno que otro curso de antropología, nos enseñaban a distinguir a los grupos humanos según la forma de su cráneo. Guardo vagos recuerdos: había gente "dolicocéfala", "braquicéfala”, etc. Por supuesto, lo que estaba detrás de esta antropología física, era la idea de raza humana, y detrás de la idea de raza humana, rápidamente venía el racismo.

Luego llegaron Lévi-Strauss y otros, y la antropología se tornó cultural. Pero allí también, y me voy acercando al punto central, la idea de cultura estaba bastante alejada de la que tenemos hoy. La idea de cultura se alineaba con la de reproducción. Iba con la idea de que una cultura es un conjunto de comportamientos, valores, costumbres, tradiciones que se reproducen. Claro, la reproducción no siempre es fácil. La modernidad, mediante el dinero, el capital, las migraciones, el colonialismo, etcétera, destruye las culturas tradicionales.

Sin embargo, se seguía definiendo la cultura en su dimensión esencial y eterna, y en ningún momento desde el punto de vista de lo que hoy me parece ser una característica central de lo que llamamos las identidades culturales, es decir, el cambio. Por lo tanto, me parece que la antropología se interesó durante muchos años en fenómenos culturales considerados desde la perspectiva de su estabilidad, su voluntad de permanencia.

Hoy en día, sean las que sean las sociedades que estudiamos, hasta las más alejadas del llamado mundo moderno, creo que debemos aceptar la idea de que las identidades culturales, y por lo tanto, las culturas, permanentemente se transforman.

A veces la transformación se hace recuperando antiguas tradiciones o costumbres. La palabra que utiliza Lévi-Strauss es bricolage. Es decir, se recuperan viejas tradiciones para inventar algo nuevo. Me parece que cada vez hay más transformaciones en las identidades culturales, y más que lógicas de reproducción, debemos aprender a distinguir lógicas de producción. Nuestras sociedades, desde las más tradicionales hasta las más "modernas", producen, inventan, fabrican diferencias culturales.

Podría demostrárselo como sociólogo, recurriendo a casos extremos. Resulta que me interesé mucho por el problema de la producción de identidades. Les puedo dar varios ejemplos sorprendentes. Sólo voy a dar uno, francés. Aquellos que conocen Bretaña, en Francia, o piensan algún día visitar esta región, se han percatado de una identidad bretona sumamente poderosa y viva. Existen escuelas en las que los niños aprenden el bretón. Cada año se dan festivales de música bretona a los que concurre muchísima gente. Hay una arquitectura bretona, etc. El discurso de los actores suele ser el siguiente: "Reproducimos nuestras tradiciones, resistimos, no dejamos que nos aniquile el jacobinismo francés centralizador, ni el 
capital que destruye las culturas con el dinero; resistimos. Nuestra cultura se reproduce."

Pero si uno se acerca un poco a esta cultura, se sorprende: la lengua bretona, los niños que hoy la aprenden, vienen de una clase media más bien acomodada, y aprenden una lengua que si bien sigue siendo bretón, ya no es la lengua que hablaban los abuelos o los tatarabuelos, cuando la hablaban, y que era una lengua de pobres, de campesinos.

La música bretona, hagan ustedes mismos la experiencia, escuchen un día a cualquier grupo de música bretona - es sin duda lo más dinámico de la cultura bretona- es algo completamente bretón y a la vez completamente nuevo: hace dos o tres siglos no se podía imaginar algo similar. En cuanto a la arquitectura bretona, les puedo decir porque leí al respecto cosas muy serias, está copiada de la arquitectura del siglo XVIII de la región de Ile de France.

Quizá exagero un poco. Es para decirles que la cultura que se reproduce es en realidad una invención, una producción, una transformación. Por lo tanto, me parece que la antropología, más que cualquier otra ciencia humana y social, tiene que aceptar la idea de que la cultura que estudia está en movimiento, está cambiando, sigue una lógica de producción. Ésta conduce a veces (y aquí es donde se complican las cosas) a formas relativamente estables que tienen cierta continuidad histórica; pero en otras ocasiones, conduce a formas totalmente inestables, en permanente transformación, incluso mediante procesos que podemos llamar de mestizaje cultural, de hibridación, de mezcla.

Ya tenemos un primer trastorno de las concepciones tradicionales que se tienen de la antropología, pero creo que debemos avanzar aún más. Debemos observar cómo se construyen, cómo se inventan, cómo se producen las culturas que obligan a las ciencias sociales a considerar la cultura desde un punto de vista dinámico y no desde un punto de vista de la reproducción.

Lo que a mí me llama la atención es que no podemos entender esas transformaciones sin abordar el trabajo autoreflexivo desarrollado por aquellos que están en el centro de las transformaciones. Y si queremos abordar el trabajo de los actores, tenemos que introducir la no- ción sumamente importante de sujeto o subjetividad. Estamos en un campo en el que faltan las palabras, creo que habría que introducir la noción de subjetivación, pero estamos pisando un terreno delicado en el que se recomienda cierta cautela.

En todo caso, lo que me parece cierto es que cuanto más se dan lógicas de producción de identidades culturales, más debemos considerar que aquellos que están a cargo de la producción lo hacen a partir de su subjetividad. Actúan como sujetos, y a veces, como sujetos personales, individuales.

Lo repito, y es una idea que me importa mucho: es a través de iniciativas, de decisiones personales, eminentemente subjetivas, como las identidades colectivas se transforman.

Lo diré de otra manera: creo que ya no debemos preguntarnos si se debe escoger entre dos formas de ver al mundo actual, una que nos sugiere que hay cada vez más individualismo, y por tanto, subjetividad; y la otra, que hace hincapié en tribus, identidades culturales colectivas, comunidades. ¡No! No hay que escoger entre estos dos fenómenos, pienso que el primero alimenta al segundo.

Cada vez más el individualismo moderno conduce a elecciones y decisiones en las que la gente dice: "Yo hago — de manera más o menos deliberada, claro está-, tomo la decisión de adoptar tal o cual identidad, de participar en tal o cual comunidad, de verme involucrado en tal o cual religión", etc. Me parece que debemos aprender en las ciencias sociales a no oponer el individualismo moderno, en sus dimensiones de referencia al sujeto, al comunitarismo, a las identidades, etc. Debemos aprender a pensar las dos cosas de manera articulada.

Por lo tanto, hay un vínculo entre las transformaciones culturales y la subjetividad personal, que tiene una consecuencia muy importante en las culturas. Mientras más susceptibles se muestren en involucrarse en una identidad colectiva a partir de una subjetividad personal, mas se puede pensar que las personas quieren mantener esa subjetividad, es decir, esa capacidad de reflexión, de deliberación, de pensar en lo que están haciendo. Cuanto mayor sea su capacidad de involucrarse, comprometerse, mayor va a ser su capacidad de desvincularse. Entra- 
mos, pues, en un mundo, en el que las identidades están constituidas por gente que entra y sale, que se mezclan o no con los demás, en forma estable o inestable. Todos los casos son posibles.

Me parece, entonces, que se derivan consecuencias muy importantes para la antropología: 1) tiene que aceptar la idea de que cuando estudia las culturas, éstas pueden estar en movimiento; 2) si este es el caso, tiene que interesarse cada vez más por la subjetividad personal de lo que estudia, lo cual no está siempre en los hábitos de todos los antropólogos. No quisiera generalizar, por supuesto.

Por lo tanto, me parece que la antropología no puede apartarse de una tendencia general, que observo por mi parte con mucha claridad en la sociología, y que consiste en colocar la noción de sujeto en el centro del análisis.

Entonces me van a preguntar: “¿Qué es el sujeto?” Es una noción que ha generado inmensas discusiones, toda la filosofía lo debate desde el principio, y no voy a resolver el problema en dos patadas. Sólo les diré cómo, en una primera aproximación, defino al sujeto: es una virtualidad, es la capacidad que cada ser humano tiene, trolar su existencia. Es la posibilidad, la virtualidad, de volverse eventualmente actor de su existencia. Aceptar esta definición implica un principio básico: cualquier otro ser humano aparte de mí debe tener la posibilidad de ser sujeto, controlar y construir su experiencia.

Puesto que estoy a punto de concluir, quise hacer hincapié en lo que me parece estar en el centro de un cambio necesario de paradigma. Algunos ya hicieron el cambio; otros van a resistir, y seguramente con muy buenos argumentos — nunca dije que toda la antropología tiene que tomar este camino-, pero me parece que estamos en un momento histórico de la historia de las ideas y del trabajo de todos aquellos que no sólo se conforman con ideas, sino que también quieren hacer trabajo de campo en el que se trata de aceptar cada vez más los dos puntos a los que aludí: 1) que la cultura se transforma, 2) para entender la transformación, cabe preocuparse por la noción de sujeto personal, singular.

A partir de ahí se puede intentar hacer observaciones más superficiales acerca de los objetos de la antropología hoy en día. Creo que es una de sus preocupaciones.
El objeto principal, por supuesto, sigue siendo el estudio de las comunidades humanas y sus culturas. Pero me parece también que hay otro tipo de objeto posible para la antropología: estudiar las dimensiones más oscuras, más inquietantes, que podemos asociar con esta idea de producción de identidades culturales. Dos me parecen centrales: 1) el estudio del racismo; 2) el estudio de la violencia.

Pienso que es interesante estudiar estos fenómenos a la luz de lo dicho. Es decir, estudiar la cara obscura, negativa, de las transformaciones de la cultura y del papel que puede desempeñar el sujeto en este fenómeno. Es cierto que esto nos lleva muy lejos, pero lo digo porque conozco cada vez más antropólogos que se interesan por la violencia y que se molestan por la idea clásica que ve a la violencia en su forma más pura, como lo que escapa a todo lo social, cultural, y que asumen a la violencia como la parte del ser humano que aparece cuando todo lo otro ha desaparecido. Debemos pensar de otra manera. El antropólogo puede mirar a la violencia, incluso a la violencia extrema.

En cuanto al racismo, los antropólogos han sido de los primeros en reflexionar sobre el tema. De hecho, los antropólogos han contribuido a la "producción" de racismo. Pero debemos insistir también en el hecho de que entre los antropólogos es donde encontramos la mejor defensa para refutarlo.

Una última observación: si es pertinente lo que he dicho, esto implica que la antropología debe volverse global. Global en el sentido de que debe circular entre lo que atañe a lo más íntimo, la noción de sujeto, y la reflexión en el ámbito de un planeta donde los grupos susceptibles de ser estudiados por la antropología son grupos distantes pero interconectados a este proceso de globalización del que tanto hablan los economistas.

Quiero decir que la reflexión del antropólogo de hoy, como científico social, debe ser capaz de alternar, por un lado, entre tomar en cuenta el aspecto más subjetivo, más personal y; por el otro, ir a lo más general, lo más global, lo más planetario, apoyándose, evidentemente, en una reflexión histórica y política.

Termino con un señalamiento acerca de las fronteras de las disciplinas. Me parece que he hablado suficientemente de la relación entre la antropología y la sociolo- 
gía. Sólo diré que, en efecto, hay colegas sociólogos que investigan sobre campesinos indígenas en alguna región y al mismo tiempo, antropólogos que estudian a los mismos campesinos indígenas: las diferencias entre ambas aproximaciones están a punto de desaparecer.

Sin embargo, deseo insistir sobre otras disciplinas. Me parece que son muy interesantes las cuestiones de frontera, por una parte, con las ciencias cognitivas y, de otra, con la filosofía política.

Las ciencias cognitivas, de las que no me atrevo a hablar mucho, por mi incultura, pero de las que puedo decir que es importante saber que caminan un poco sobre nuestro terreno, tanto de la antropología como de la sociología. Las ciencias cognitivas progresan y proponen reflexiones que ocupan ámbitos nuestros y esto lo digo con precaución.

La segunda disciplina, que conozco mejor, es la filosofía política. Para mí no es una ciencia social pues no nos dice qué pasa; nos habla sobre lo que es justo o injusto, sobre lo bueno o no bueno, lo que es aceptable o inaceptable dentro del mundo en que vivimos. Pero afirmo que en el gran debate de los últimos veinte o treinta años sobre las cuestiones aquí tratadas, en el asunto de las diferencias culturales, de identidades, etc., la filosofía política ha sido la pionera.

Aún más interesante es el hecho de que la filosofía política era una disciplina moribunda en las décadas de 1950 y 1960, hasta que llega John Rawls, quien publicó en 1981 su libro Una teoría de la justicia. Después de él, se abre el debate en el que, simplificando mucho, tenemos a gente que se dice "liberal" y otra que se considera "communitarian", y que ha provocado una inmensa discusión desde hace treinta años alrededor de los temas que aquí he abordado. Los sociólogos, los antropólogos, los politólogos, se han quedado detrás de la filosofía política. Nos hemos rezagado.

Cuando pienso en los personajes claves de este debate, ya no pienso ni en antropólogos ni en sociólogos, pienso en Charles Taylor, Michael Walzer, Will Kymlicka, en filósofos políticos. Creo que no debemos sentirnos amenazados, pero sí reflexionar sobre las relaciones que existen con la disciplina de la filosofía política y evaluar cuál es nuestra fuerza y cuál es su debilidad; nosotros sí sabe- mos lo que es el terreno, lo que es eso de producir conocimientos y no sólo discutir. Pero debemos dialogar cada vez más con esta disciplina.

La gran transformación del mundo contemporáneo nos da la ocasión de operar una transformación en nuestras maneras de pensar, nuestras formas de apropiarnos de los objetos que estudiamos y de discutir con las demás disciplinas.

\section{Teresa Sierra:*}

Quisiera retomar un punto y hacerle una pregunta en relación con la cuestión del aspecto de la subjetividad y de los sujetos. Usted habló de la importancia e insistió en el aspecto de que no hay que contraponer el individualismo con el ámbito de lo colectivo, sino que los dos son elementos centrales para comprender esta problemática de la diversidad en la perspectiva de las culturas que se transforman, pero yo me pregunto si realmente esta posibilidad de elección personal —a la que usted está apuntando- es tan igual para todos. Creo que si bien las identidades se negocian y que sin duda no podemos hablar de identidades esenciales, y sí de que se transforman, no todos tenemos la misma posibilidad de elegir. Sobre todo hablando de racismo, esto es muy claro en ciertos grupos socioculturales. Quisiera que profundizara un poco más en esta concepción.

\section{Michel Wieviorka:}

Es una pregunta importante. Evidentemente, no todo el mundo es sujeto fácilmente, y mientras más estamos dominados, menos fácil es ser sujeto. El caso extremo es lo que llamamos la alienación, la incapacidad de pensarse a sí mismo y la obligación de experimentar, lo que Pierre Bourdieu llamó una violencia simbólica; es decir, apropiarse, sin estar conciente, de las categorías del dominante. Pero es justamente en este caso que una teoría sobre el sujeto podría ser interesante. Lo explicaré a propósito de la violencia, que es una cuestión que me interesa enormemente.

\footnotetext{
* Teresa Sierra es doctora en sociología por la Universidad de París y profesora-investigadora del CIESAS.
} 
Hay, en ciertas experiencias de violencia, aspectos que pueden llevarnos a tres o cuatro sub-teorías del sujeto, o sub-elementos de un acercamiento en términos del sujeto. Intentaré indicarlos para darme a entender. Si considero, para comenzar de manera muy sencilla, un cierto número de actos de violencia urbana en un cierto número de sociedades industriales me percato que esta violencia urbana proviene de los jóvenes que, de alguna manera, tienen el sentimiento de no poder construir su existencia, de gente que no puede construirse como sujeto. Entonces, una primera idea muy elemental es que, en ciertos casos, la violencia surge cuando estamos deseosos de construirnos como sujetos pero que no podemos hacerlo. No somos reconocidos, somos despreciados, somos excluidos socialmente, etc. Esta es una idea elemental todavía.

Un segundo caso que quisiera evocar es el de la cuestión de la crueldad. Todos los antropólogos quedan fascinados por la cuestión de la crueldad cuando se topan con la violencia, es algo que siempre me ha interesado mucho. En general, son varias las explicaciones que se dan, algunas más o menos instrumentales. La crueldad es lo que aterroriza a todo el mundo y que impide reaccionar al aterrorizado.

Pero creo que hay otra cosa que sucede a menudo. En la crueldad, la idea de prohibirle al otro ser sujeto, la idea de que el otro no puede ser humano y de que por lo tanto lo voy a tratar de manera cruel, se da tal vez para que yo pueda seguir considerándome como sujeto. Existe una frase magnífica, que guardo en la memoria, de Primo Levi, este judío italiano que estuvo en un campo de concentración y que después escribió magníficas páginas. Un día reflexionó sobre la crueldad de los guardianes de los campos nazis y dijo algo así como: “¿Por qué son más crueles de lo que sus funciones exigen?" Son crueles para poder hacer lo que tienen que hacer, es decir, para poder hacer cosas inhumanas tienen que tratar al otro como una no persona humana. No entraré en discusiones tan precisas, pero este es un segundo caso.

Hay un tercer caso que me parece muy interesante y que me remite, por ejemplo, a los famosos experimentos que realizó el psicosociólogo Stanley Milgram en los años setenta. Algunos de ustedes deben conocer estos experimentos, los evoco simplificándolos al extremo. La idea es la siguiente: le pide a los estudiantes ponerse de un lado de una pared de vidrio, en el otro lado se encuentra alguien sentado en una silla. Entonces el profesor le pide a un estudiante que mande corriente eléctrica, ya que están haciendo un experimento sobre la resistencia al dolor. El estudiante manda corriente eléctrica, y cada vez que avanza la palanca ésta aumenta. La persona que está sentada en la silla del otro lado y que recibe la corriente cada vez más fuerte, se retuerce de dolor y los dolores son cada vez más tenaces. Llega un momento en que parece que está muriendo. Evidentemente, la persona que está sentada en la silla es un actor pagado para representar ese sufrimiento.

Finalemente, la pregunta interesante que se plantea es: ¿Qué es lo que hace que un estudiante estadounidense de los años setenta sea capaz, en nombre de un experimento, de imponer un dolor tal a un ser humano que manifiestamente no lo amenaza? La respuesta de Milgram es: "la sumisión a la autoridad, la obediencia".

$[\ldots]^{\star}$ me parece que más allá de las explicaciones clásicas sobre la violencia, puede ser interesante introducir la noción de sujeto, no para decir que es el sujeto el que se expresa en la violencia, sino para plantear que la ausencia de sujeto, la imposibilidad de ser sujeto, la no subjetividad a un momento dado, etc. - pongo en relación la hipótesis del sujeto y un fenómeno de violencia- es lo que explica cierta conducta violenta. Eso es lo que tenía en mente, no digo que todo se explica por el sujeto, sino al contrario, también con elementos como los presentados.

Pienso que podemos reflexionar en el racismo también con esta clase de noción. No les planteo esto para decirles cómo hay que hacer, sino para señalar simplemente que la noción de sujeto puede ser muy útil, hasta como un hueco al revés, para reflexionar en un cierto número de fenómenos que clásicamente los antropólogos estudian.

\section{François Lartigue:**}

Estamos profundamente en concordancia y superficialmente con disonancias. Tenemos la suerte de pertenecer

\footnotetext{
* Laguna en la transcripción.

** François Lartigue es profesor titular-investigador del CIESAS.
} 
a una de esas instituciones, el CIESAS, misma que ha planteado desde hace treinta años estos problemas, que se ha preguntado cómo trabajar en las ciencias sociales, y en particular desde la antropología.

Estas cuestiones fueron la base de las actividades del programa de trabajo y de formación desde la antropología de científicos sociales en el CIESAS. De manera interesante estos aspectos fueron planteados por evolucionistas, ligados a la tradición del "neoevolucionismo" estadounidense y más profundamente, del marxismo crítico, pero muchas de las comprobaciones de las crisis de los paradigmas no vinieron fundamentalmente del funcionalismo a la Parsons, sino también a partir de muchas otras perspectivas.

Creo que hoy, particularmente cuando estamos teniendo que confrontar la necesidad de comprender dosis inéditas de violencia, de crueldad, nuevas formas de racismo, es muy importante para muchos de nosotros la reflexión crítica alemana que se genera con anterioridad con base en la necesidad intelectual y política de dar cuenta del nazismo que tienen los intelectuales alemanes.

Eso me lleva a una referencia, por cierto, sobre la problemática de las identidades. Quiero mencionar a un seguidor de Primo Levi, a Giorgio Agamben, un filósofo italiano, quien, precisamente, en textos recientes, está reflexionando acerca de la necesidad o la conveniencia de repensar la problemática de las identidades a partir de Auschwitz. En esto de pensar en lo que hay de nuevo en las identidades, efectivamente, encontramos algo como la responsabilidad, quizá, de dar cuenta de lo que los problemas de la identidad pueden conllevar, de su enorme impacto. Auschwitz, y lo que significó para la reflexión, para todos los que han tratado de pensar o plantear desde la filosofía o desde las ciencias sociales, los desafíos de lo inédito, el mundo presente, las transformaciones, etcétera.

Respecto a las disonancias. Nos habló de paradigmas, de objetos, no nos habló nunca de los modos de aproximarse a ellos y pienso que ahí es donde podemos encontrar todavía eso que las ciencias sociales comparten. En todo caso, sí creo que la teoría que manejan los antropólogos es profundamente una teoría sociológica. Hay cuestiones compartidas en cuanto a los modos de acerca- miento, pero también diferencias interesantes y desafíos. Insisto, hace treinta años que aquí estamos tratando de ajustar nuestros instrumentos de acercamiento a estas problemáticas y, por cierto, tenemos la suerte de trabajar muy estrechamente los antropólogos, los sociólogos, alrededor de los mismos objetos, las mismas situaciones y tratando de ver cómo nos dividimos la tarea, cómo nos complementamos o simplemente, cómo aprovechamos esa cierta diferencia de perspectiva para tratar de avanzar un poquito.

\section{Michel Wieviorka:}

Yo hablé a partir de mi itinerario personal. Nunca he sido formado por el funcionalismo parsoniano, personalmente me formé en la crítica de este funcionalismo. Por lo tanto, eso explica un poco la manera como describí las cosas, pero reconozco que es un caso particular, y a través de caminos diversificados hay ciertamente muchas confluencias, y eso es lo revelante. Varios investigadores vinieron del pensamiento crítico, del marxismo. Yo mismo fui empapado de marxismo durante quince, veinte años.

Lo que me parece importante es hacer dos o tres observaciones. La primera: dice usted "Auschwitz". Diría yo "la experiencia nazi", porque nos obliga a reflexionar acerca de muchas cosas. La experiencia nazi no es sólo Auschwitz, es decir, simplifico, la muerte organizada de manera casi burocrática, casi industrial. Sigmund Boehman, al que considero como sociólogo, explica que esto representa la cumbre de la modernidad.

La experiencia nazi es también la gente que se fue al frente oriental. Ellos no eran los que ponían a los judíos en los trenes, etcétera. No, estaban allí para fusilar, masacrar masivamente a la gente y confrontarse con la muerte que daban. Es muy interesante, cuando uno lee los testimonios escritos de este lado de la experiencia nazi, uno empieza a preguntarse varias cosas. Sólo voy a citar un libro muy importante, de un historiador anglosajón, Christopher Browning, que cuenta la historia a partir del juicio de esa gente en cuestión, en los años sesenta, setenta, en Hamburgo. Leyó todos los archivos. Cuenta la historia de un batallón, reservistas, buena gente, para nada ideólogos nazis, que fueron obligados a ir al frente $\mathrm{y}$ cometer todas esas masacres. 
Uno se pregunta muchas cosas: ¿acaso estamos ante lógicas de sumisión a la autoridad?, ¿acaso estamos ante lógicas de sadismo y crueldad? La experiencia nazi nos invita a "manipular" todo tipo de paradigmas interesantes. Es una experiencia hoy en día muy documentada, mucho más que otras, por lo tanto sabemos muchas cosas, lo que permite abordarla bajo una multiplicidad de ángulos.

Quisiera hacer una observación superficial y otra más importante. La superficial: estoy descubriendo su institución. La institución a la que pertenezco, la Escuela de Altos Estudios en Ciencias Sociales, se creó un poco bajo el mismo enfoque, con investigadores que quisieron salirse de la vieja Sorbona, y me parece que sigue existiendo un problema real: el sistema de formación general, nacional e internacional, está organizado en disciplinas. Casi es criminal formar a estudiantes en el cruce de varias disciplinas. Si bien van a tener una formación intelectual ejemplar, cuando se presenten ante los sociólogos les van a decir: "Vaya usted a buscar trabajo con los antropólogos, ya que es más bien su formación”; y los antropólogos les dirán: "Mejor vaya usted con los historiado- se impone a partir del momento en que pongo en relación el objeto que quiero estudiar con mis ideas generales. Por supuesto, no es tan sencillo. Pero les voy a dar un ejemplo, y aquí hablo como sociólogo.

Quiero saber cuál es el comportamiento de consumo de los hombres y las mujeres, o si la gente compra coches de color claro o más bien de color oscuro, según su edad, etcétera. Si quiero transcribir mi pregunta de investigación en términos metodológicos, veo muy bien la encuesta que hay que hacer: voy a pedir a los entrevistados, por un lado, que me indiquen sus opiniones; y por el otro, voy a medir variables más objetivas, la edad, el sexo y relaciono todo. Hago una encuesta cuantitativa, estadística, y pienso técnicamente en la muestra que voy a seleccionar.

Si quiero entender ahora, como sociólogo, lo que significa "ser prisionero", “qué es la experiencia carcelaria?", experiencia que podría estar en el origen de varios movimientos de protesta, por supuesto, no voy a recurrir a un método de sondeo de opinión, sino a la observación participativa. Me voy a acercar lo más posible.

Por lo tanto, mi respuesta a su pregunta es la siguiente: no creo que existan métodos "rey", casados con una disciplina, creo que existen métodos más apropiados que otros, que vamos descubriendo o inventando en función de los objetos estudiados y de nuestras orientaciones generales.

Le voy a decir una cosa. Hice traducir al francés un libro de un sociólogo estadounidense, William Footwhite, titulado Street Corner Society, que para mí es uno de los diez o veinte libros más importantes de sociología. Permítanme decir a los antropólogos aquí reunidos: si quieren un buen manual de observación participativa, lo van a encontrar en el libro de este sociólogo. Es un libro excelente, con un anexo, excelente también. Todo para decirles que no hay método rey. Es mi respuesta profunda.

\section{Sergio Puente:*}

Antes que nada, lo que dijo me "alivia", pues en un principio me sentí como un intruso porque no soy del

\footnotetext{
* Sergio Puente es doctor en geografía por la Escuela en Altos Estudios de París y urbanista e investigador del Centro de Estudios Demográficos de El Colegio de México.
} 
CIESAS ni antropólogo. Soy profesor de El Colegio de México y me gustaría plantear unas preguntas como planificador urbano.

Realmente me pareció importante lo que usted decía sobre la construcción del sujeto y cuando hacía la referencia de que el objeto del sociólogo era, más bien, un objeto de sociedades avanzadas, y particularmente urbanas, y que el objeto del antropólogo era un poco la "ruralidad", un poco las sociedades tradicionales. Cuando nos confrontamos con una ciudad como la de México, a donde el objeto del antropólogo llega por migración, estamos ante un fenómeno muy complejo que Bryan Roberts había caracterizado como la ciudad de campesinos y donde el problema de la construcción del sujeto, pero del sujeto colectivo no del sujeto individual, se plantearía realmente como un desafío brutal a la sociedad y para crear los mínimos de "ciudadanización" necesarios para la convivencia colectiva.

Desde el punto de vista que usted plantea, tal parece que la construcción del sujeto es una tarea individual y es una construcción de conciencia como actor. De ser así, epistemológicamente, ¿cuál sería el problema o la posibilidad que tendríamos de construir un sujeto social, un sujeto colectivo que haga que una ciudad sea un espacio de convivencia, un espacio de todos y no un espacio de nadie?

Tal parecería que, en el momento de entrar en interacción, la construcción de conciencia del sujeto se colocara en un proceso de cuestionamiento "intersubjetivo" hacia el otro y donde lo que realmente se requiere es la construcción de consensos, de una conciencia colectiva. ¿Sería pertinente, epistemológicamente, hablar de un sujeto colectivo? De ser así, ¿cuál sería la responsabilidad del Estado?, ¿quién debería de construirlo? o ¿cuál es la tarea individual de cada uno de nosotros? A lo que nos estamos confrontando actualmente en una ciudad como la de México es exactamente como el problema a la inversa, la deconstrucción del sujeto, la descomposición social o el tema de Maffesoli, la sociedad tribal urbana. A mí me preocupa como planificador, pues no es construir la ciudad en términos físicos, ya que en determinado momento sería la expresión simplemente "objetual" de la producción del sujeto, sino de la producción del sujeto en lo cotidiano.

\section{Michel Wieviorka:}

Voy a distinguir varios temas en su intervención, lo cual me permite ser un poco más claro:

Primero, comparto por completo sus observaciones acerca de la ciudad de México y creo que es cierto hoy en día de todas las grandes metrópolis. Cuando usted lee a Saskia Sassen, más bien socióloga, es lo que nos describe: la ciudad global, la ciudad de la mundialización es precisamente eso.

He leído varios trabajos de investigadores sobre los movimientos islamistas, entre los cuales destaco uno de un muy querido amigo, Koslo Kavar, quien estudió a los protagonistas de la revolución iraní a fines de los años setenta. Entre éstos, identificó a varios como "campesinos descampesinados", es decir, gente que llegó a la ciudad convencida de que iba a tener acceso a la modernidad, al trabajo, al dinero, al consumo, y que acaba viviendo en condiciones terribles, lo que provoca en ellos un inmenso resentimiento respecto a la modernidad. En el Irán de aquel entonces se vivía en un régimen modernizador a ultranza, lo cual radicalizó aún más a esa gente. Esto reafirma lo dicho por usted.

El segundo punto: pienso que haciendo hincapié en el sujeto individual no me aparto de lo que ha sido mi formación de sociólogo, ni de mis intereses como sociólogo desde que ejerzo la profesión, es decir, el estudio de los movimientos y actores sociales en el extenso sentido de la palabra, o movimientos socioculturales.

Mi pregunta es: ¿cómo se pasa del sujeto personal al sujeto colectivo y cómo el sujeto colectivo se transforma en actor?, lo que no es igual.

Usted hace una pregunta muy general. No creo - $-\mathrm{y}$ no me interesa hacerlo- que la subjetividad personal pueda estudiarse en sí misma. Anteriormente hablé de una virtualidad, de una capacidad. Pero, cómo decirlo, el sujeto se vuelve sujeto colectivo cuando hay movilización, cuando se involucran intelectuales o actores más políticos que estructuran ideológicamente la acción, por ejemplo.

Pienso que no es imposible pasar de la noción de sujeto personal a la de sujeto colectivo. Doy a la noción de sujeto personal un sentido abstracto, el sentido de virtualidad, es una definición no social, no cultural. El sujeto 
va más allá de la noción de actor. Tiene que constituirse. Podríamos complicar las cosas. Pero no.

No sé si le entendí bien. Pero allí donde puede ser que esté en desacuerdo con usted es en el tema del consenso. Por supuesto, un movimiento, una acción colectiva, requiere de cierto consenso interno. Pueden existir tensiones, dificultades, pero si los actores no van todos en el mismo sentido, el movimiento revienta.

En cambio, pienso que una colectividad humana, una ciudad, un distrito federal, un país, este tipo de colectividad, necesita más del conflicto que del consenso. Quizá sea la verdadera discusión, y aquí es probablemente donde encontramos la distinción más clásica entre sociología y antropología.

La sociología se interesa más por lo que socialmente divide, mientras que la antropología se interesa más bien por la totalidad cultural. Pero aquí también necesitamos matizar. ¿Por qué le digo esto? Porque vivo en una sociedad en la que sufro mucho del consenso.

Tengo a un jefe de Estado electo con $80 \%$ de los votos. Porque no queríamos al Frente Nacional, entonces una opinión respetable, pero que alcanza hoy 80 u $85 \%$ de opinión favorable porque dijo que estaba en contra de la guerra en Irak. Estoy entre los que le dieron razón.

Pero el precio que se tiene que pagar por el consenso es que ya no hay debate político en la sociedad francesa: estamos todos de acuerdo con nuestro jefe de Estado, por lo tanto, ya no se requiere debate político.

Pienso que el consenso no debería durar demasiado y espero que se reconstruyan los debates. El problema es que todos los actores no tienen la capacidad de emerger. Y todos los sujetos, incluso colectivos, no tienen la capacidad de construirse. Por lo tanto, la ciudad en la que sueño (aunque jafortunadamente no soy planificador urbano!) es la ciudad en la que se producirían conflictos institucionalizados entre grupos sociales, grupos culturales, que aceptarían discutir, negociar, pero que estarían en conflicto.

Por supuesto, complica la tarea del planificador, pero en este punto preciso es donde estaría en desacuerdo con usted. Quizá estaba dando otro sentido a la palabra consenso.

\section{Sergio Puente:}

Creo realmente que el conflicto es un factor sine qua non porque, para llegar al consenso, necesitamos primero el conflicto. Pero hay un problema real que se plantea en relación con la capacidad de aceptar y respetar la alteridad, aceptar la "otredad" no como un potencial enemigo, sino como la potencial y real posibilidad de una sinergia que permita reconstruirme también como sujeto. Entonces, no se trata del consenso como sinónimo de alineación - porque tal parece que en la sociedad francesa están alineados sobre un punto--, se trata de un consenso transitorio, el consenso como la posibilidad — como lo planteó usted, y ahí estoy completamente de acuerdode tratar de establecer la interacción no en situaciones de conflicto, sino en situaciones de una mínima racionalidad donde los sistemas culturales, los sistemas de valores, tengan una cierta flexibilidad para entender la "otredad" y la alteridad, si no va a ser el problema total y permanente de los consensos y el permanente conflicto, con lo cual hacer la apología del conflicto es hacer la apología de la violencia constante.

\section{Michel Wieviorka:}

No estoy de acuerdo, pero todo depende del sentido que le damos a la palabra conflicto. Voy a ser muy paradójico. Voy a defender la posición completamente opuesta: más conflictos hay, menos espacio hay para la violencia.

Le doy un pequeño ejemplo que le va a interesar en tanto que planificador urbano: en una pequeña ciudad de la periferia de Lyon, segunda o tercera ciudad de Francia, llamada Vaux-en-Velin, hubo en 1990 un motín muy importante, el motín urbano más importante que Francia haya conocido. ¿Por qué el motín? Porque algunos jóvenes se habían enterado de que la policía había cometido otro "error”. ¿En qué consistió el error? La policía le ordena a una moto o un coche detenerse, pero como se trata de un vehículo robado, no se para. El policía dispara - no tiene derecho a hacerlo- y mata al joven. Motín, violencia, tiendas, coches destruidos, etcétera.

Entonces, se crea en la ciudad una organización, incluso varias, pero la más interesante de ellas se llama "Ágora”. Es una asociación de jóvenes que dicen: "nosotros vamos a representar a los jóvenes de esos barrios, 
vamos a condensar en nuestras intervenciones todo lo que piden los jóvenes y vamos a conflictualizar sus demandas. Pedimos que la policía se comporte de otra manera, que se construyan equipamientos deportivos así como lo quieren los jóvenes y no como el ayuntamiento cree que ellos quieren, que se crean equipamientos culturales, transportes públicos eficientes", etcétera.

La asociación entra en conflicto con el poder municipal local, porque exige: "queremos esto, lo otro, los jóvenes quieren esto, lo otro". Pero, ¿qué dice esta asociación cuando los poderes locales les reprochan pedir siempre las cosas en forma conflictiva? Les contestan: “¿Prefieren ustedes la violencia? Discutan con nosotros en vez de dejar que la violencia emerja por olas totalmente imprevisibles."

Por lo tanto, tomo este ejemplo para que me entiendan bien: el conflicto institucionalizado entre esta asociación y el poder local es mucho mejor que la emergencia de violencia por motivo de un episodio u otro y en el que todos son infelices: los jóvenes, porque por supuesto la violencia no les aporta nada, los responsables políticos de la ciudad, todos sufren, en cierta forma, de la no conflictualización de los problemas sociales. Por eso opongo el conflicto a la violencia. Pero es una inmensa discusión.

\section{Patricia Torres:*}

Un pequeño comentario, una preocupación. Escucho tu propuesta de sujeto, este sujeto que debe devenir en persona, no sólo ser, en esta sociedad global, en esta sociedad donde bien notas que de algún modo se van borrando las diferencias; por otro, surgiendo otras nuevas, y no puedo más que recordar el artículo de Sombart, su definición de capitalismo, escrito alrededor de 1936 en la Enciclopedia de las Ciencias Sociales. Me viene a la mente porque recuerdo con sorpresa cómo Sombart va definiendo que en una sociedad capitalista industrializada, que iba a ser cada vez más abierta por el mercado y la intervención, el individualismo, que es central en la discusión filosófica

* Patricia Torres es doctora en antropología cultural por la Universidad John Hopkins, Baltimore, y subdirectora de docencia del CIESAS. del capitalismo, se iba a ver en la contraparte de una producción masiva que iba a tener que vender su producto de una manera que aparentase el individualismo, es decir, casas hechas en serie pero con colores distintos, zapatos de todas tallas hechas en fábricas iguales por gente igual pero con tonalidades de piel, de listones, etc., diferentes, para que la gente pudiera decir: "estoy eligiendo".

El sujeto puede elegir en una diversidad construida no por el sujeto. Pregunto, entonces - ya que concluías la respuesta a François respecto a dónde están las disciplinas, dónde están las profesiones—, ¿no será parte de esta máscara?, ¿de que podemos escoger ser sociólogos, antropólogos, historiadores, etcétera, pero realmente en la base estamos siendo algo más que ello?

\section{Rafael Loyola:*}

Si me lo permiten, tengo una pregunta que va en la misma dirección que la de Patricia Torres y tiene que ver con lo siguiente: ¿las disciplinas, en la actualidad, tienen los instrumentos para abordar por sí solas los nuevos fenómenos sociales? En este sentido está claro cómo se han venido borrando las fronteras disciplinarias entre la antropología y la sociología, pero yo me pregunto: ¿y con las otras disciplinas, qué está pasando?, ¿cuál es el impacto de las otras disciplinas?

No sé cómo sea en el caso francés, pero en lo que se refiere al caso mexicano me encuentro cada vez más con un número creciente de estudiantes mexicanos que quieren estudiar en el extranjero porque las opciones formativas que se les dan en México en las distintas disciplinas de las ciencias sociales,ya no les llenan sus expectativas para volver a abordar los problemas que a ellos les interesa estudiar.

En ese sentido, entiendo que en la escuela francesa por lo que comentabas la otra vez, están muy bien delimitadas las fronteras disciplinarias, pero eso, ¿qué tanto ayuda a resolver esta problemática? Dicho de otra manera: ¡las ciencias sociales francesas han sabido transfor-

\footnotetext{
* Rafael Loyola es doctor en historia y civilizaciones por la Escuela de Altos Estudios en Ciencias Sociales de París y director general del CIESAS.
} 
mar sus paradigmas, conceptos, visiones para abordar los nuevos sujetos? Eso hace que en el caso mexicano nos preguntemos si nuestras disciplinas se han transformado lo suficiente para poder abordarlos y de no ser el caso, a lo mejor por eso pensamos en la pluridisciplina.

\section{Michel Wieviorka:}

De hecho, son preguntas que se complementan pero que se distinguen un poco. Respecto a la primera, seguramente leí el texto de Sombart hace mucho tiempo, pero me parece que la respuesta al problema que plantean de esta descripción del individualismo, de esta concepción del individualismo, es en realidad una pregunta que nos obliga, y no soy el primero en hablar de esta manera, a distinguir dos dimensiones totalmente distintas en lo que llamamos el individualismo moderno.

Existe lo que llamé el sujeto, es decir, esta virtualidad o esta capacidad de cada uno, de dominar tal vez - bajo ciertas condiciones - sus experiencias. Esto por una parte. Existe, además, la otra definición, la otra fase del individualismo que es la posibilidad desigual, según las permodernidad de manera individual, la posibilidad de participar, el hecho de consumir zapatos, autos, etcétera. El hecho de tener acceso al consumo, al dinero, al empleo, a la salud, a la educación, como individuo, es diferente a construir su existencia. Quiero decir que las lógicas del individuo son lógicas de consumo, las lógicas del sujeto son lógicas de producción de su propia existencia. Me parece entonces que la discusión se esclarece un poco si aceptamos estas dos dimensiones del individualismo moderno. Hay un filósofo político en Francia, Alain Renaud, que explicó muy bien, mejor que yo ahora, esta diferencia. Me parece tal vez que es desde esa visión que se puede discutir mucho mejor el texto de Sombart.

Estos nuevos fenómenos sociales, de los que finalmente acabamos de hablar, tienen algo muy interesante (lo voy a decir exagerando un poco): son nuevos y al mismo tiempo antiguos; nos regresan a lo que había antes, antes de la era industrial, tal vez a los primeros tiempos de la modernidad. Sólo doy un ejemplo: estamos todos impresionados por la cuestión religiosa, para tomar un ejemplo muy amplio. La cuestión religiosa se desarrolla en el

mundo entero, da resultados totalmente inimaginables.

Yo vengo de Francia, un país cristiano. Francia es clásicamente un país católico con un pequeño porcentaje de protestantes y algunos judíos. Pero vayan a visitar una ciudad como Evry, suburbio del sur de París, o Sarcelles, suburbio del norte de París. Son casos un poco extremos, pero uno llega a Sarcelles y se topa con una comunidad judía muy importante. También hay una comunidad asiro-caldea - hasta hace poco todavía ignoraba lo que eran los asiro-caldeos, es una variedad del cristianismo un poco particular del Medio Oriente. Hay además toda una serie de iglesias evangelistas, pentecostesas, nada que ver con el protestantismo francés clásico; y también musulmanes. En un mundo muy diversificado, existe toda una gama de religiones.

$\mathrm{Si}$ van a Evry es la misma cosa. Hace unos meses, en esa ciudad se inauguró un Buda de varios metros de altura, el más alto de Europa. Francia cuenta con decenas de miles de budistas, pero me dirán que no es verdaderamente una religión. Pero bueno, los budistas de los que hablo no son solamente inmigrantes venidos de países budistas, son personas que han elegido ser budistas. Estos son fenómenos que de alguna manera nos dan la impresión de regresar hacia atrás, y lo que es nuevo es tal vez un "pre" de algo, lo que es "post" es tal vez un "pre". Esto merece una reflexión, por supuesto.

A partir de eso, me cuesta trabajo aceptar la idea de que existen las ciencias sociales francesas, las ciencias sociales estadounidenses, etc. Estoy convencido, y estamos de acuerdo, de que cada país tiene inmensas especificidades: podríamos hacer un ejercicio muy simple y pedirle a un estudiante del mismo nivel en diferentes países de hacer una tesina sobre tal o cual tema, el resultado en promedio, será bastante diferente de un país a otro. Voy a dar un ejemplo que siempre me ha sorprendido, los franceses son muy provincianos. Si se hace una tesina cualquiera, los franceses siempre citarán a Alain Touraine, Pierre Bourdieu, Michel Grozier, Raymond Aron, Raymond Boudon, los autores franceses. Tal vez vagamente a Habermas, pero nunca van más lejos. Si ustedes se van a Italia, es el contrario, no citarán ningún autor italiano, citarán a autores alemanes, estadounidenses, franceses, ingleses, a Anthony Giddens en cada línea, a 
Habermas, a Charles Taylor. Por supuesto que exagero, pero es para decir que hay diferencias.

Me daría gusto que Francia fuera un país faro, que Europa fuera un continente faro para las ciencias sociales, no estoy seguro que así sea. Pienso que la gran cosa es la capacidad de tener relaciones internacionales, de hacer circular a la gente. Comprendí muy bien el problema planteado, lamento por ejemplo que muchos estudiantes mexicanos vayan a París con el sistema del Conacyt y que no sea recíproco, que sean pocos los estudiantes franceses que vienen a México.

Les diré algo que les va a sorprender: estaba ayer en una reunión sobre problemas muy cercanos a los que hemos discutido hoy, en la que hablaron de México como un país que no está al tanto en lo que concierne la discusión de la globalización, etcétera. Me puse furioso porque cuando vengo a México - podemos pensar lo que queramos del subcomandante Marcos, del zapatismo- vengo al país del movimiento zapatista, es decir, al país de un actor que ha hecho cosas, que podemos po- ner en duda cuando lo conocemos bien, pero que en su conjunto ha sabido articular una afirmación cultural, demandas de justicia social, demandas por la democracia en el marco de un Estado-nación que no estaba puesto en tela de juicio, movimiento que además ha sido tal vez el primer actor contra la globalización neoliberal, con el famoso encuentro de 1996. Entonces, cuando vengo a México, llego a un país que puedo admirar primero por eso, y siento que hay muy pocos franceses que vienen a estudiar estos problemas. No lo digo para hacer la apología del subcomandante Marcos...

No tengo respuestas más precisas a la pregunta de $\mathrm{Ra}$ fael Loyola. Creo que la respuesta está en el intercambio de ideas, en las relaciones reales, no en las firmas de contratos entre instituciones, sino mucho más, en intercambios entre estudiantes, en coloquios, en una vida intelectual común. A mí me da gusto estar aquí y así veo las cosas. Les suplico que no tengan la imagen de las ciencias sociales francesas estupendas, yo me ahogo en Francia, estoy feliz de reciclarme al venir aquí. 